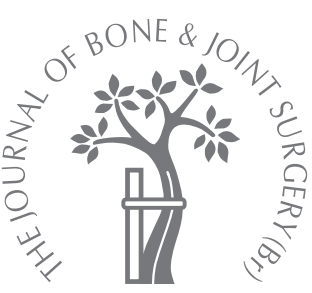

D. M. Weber,

R. Fricker,

L. E. Ramseier

From Children's

University Hospital,

Zurich, Switzerland

D. M. Weber, MD, Paediatric Surgeon

Department of Hand Surgery Orthopaedic Department Children's University Hospital, Steinwiesstrasse 75, CH-8032

Zurich, Switzerland.

L. E. Ramseier, MD, Orthopaedic Surgeon

Balgrist Orthopaedic University Hospital

Zurich Forchstrasse 340 CH 8008, Zurich, Switzerland.

n. Fricker, MD, Hand Surgeon Hand Surgery Unit, Department of Surgery

Kantonsspital Bruderholz, $\mathrm{CH}$ 4101 Bruderholz, Switzerland.

Correspondence should be sent to Dr D. M. Weber; e-mail: Daniel.Weber@kispi.uzh.ch

(C)2009 British Editorial Society of Bone and Joint Surgery doi:10.1302/0301-620X.91B9. $21906 \$ 2.00$

$J$ Bone Joint Surg $[B r]$ 2009;91-B:1213-16. Received 14 October 2008; Accepted after revision 27 April 2009

\title{
Conservative treatment of scaphoid nonunion in children and adolescents
}

This is a retrospective study of six children with ununited scaphoid fractures treated conservatively. Their mean age was 12.8 years (9.7 to 16.3 ). Five had no early treatment. Radiological signs of nonunion were found at a mean of 4.6 months ( 3 to 7 ) after injury. Treatment consisted of cast immobilisation until clinical and radiological union. The mean clinical and radiological follow-up was for 67 months (17 to 90). We assessed the symptoms, the range of movement of the wrist and the grip strength to calculate the Modified Mayo Wrist score.

The fracture united in all patients after a mean period of immobilisation of $\mathbf{5 . 3}$ months (3 to 7). Five patients were pain free; one had mild pain. All returned to regular activities, and had a range of movement and grip strength within $25 \%$ of normal, resulting in an excellent Modified Mayo Wrist score.

Prolonged treatment with cast immobilisation resulted in union of the fracture and an excellent Modified Wrist Score in all patients.

The scaphoid is the most common site of carpal fracture in children. ${ }^{1}$ For acute non-displaced fractures, most authors recommend cast immobilisation. Union without long-term sequelae can be expected. ${ }^{1-3}$ Nonunion in children is rare and is generally attributed to failure or neglect. ${ }^{4}$ Although current recommendations for treatment of delayed union and nonunion of the scaphoid in children and adolescents include both prolonged cast immobilisation and screw fixation, ${ }^{1,4}$ reports of conservative treatment are scarce. The largest case series of conservative treatment includes only four patients, ${ }^{5,6}$ whereas several relatively large case series of operative treatment of paediatric scaphoid nonunion have been published recently. ${ }^{7-11}$

The purpose of this paper was to report the outcome of a series of children and adolescents with nonunion of scaphoid fractures treated only by prolonged immobilisation.

\section{Patients and Methods}

This was a retrospective review of children and adolescents treated for scaphoid nonunion at three different institutions between 2000 and 2006. Nonunion was defined as a radiolucent line at the fracture site and cystic changes or sclerosis of the bone ends seen on standard radiographs made at least three months after injury. $^{12}$ Only undisplaced fractures were included in the review.
Six patients, all boys, with a mean age at presentation of 12.8 years (9.7 to 16.3 ) were included. None was lost to follow-up. All had a history of trauma, although only two sought immediate medical attention. All accidents occurred during sports (Table I), and all patients presented with wrist pain. At initial presentation, standard radiographs with posteroanterior, lateral and two oblique views were performed, supplemented with CT scans if displacement could not be assessed satisfactorily. One MR scan was done to confirm vascularisation of the proximal pole. Fractures occurred at the waist (five patients) and at the distal third (one patient).

Treatment consisted of immobilisation in a below-elbow cast. This was changed and follow-up radiographs taken every three to four weeks until union occurred. The parameters used to define union were absence of pain during the Watson manoeuvre13 and pressure on the anatomical snuffbox, as well as absence of a visible fracture line on plain scaphoid views. A CT scan looking for bridging trabeculae in over $50 \%$ of the cross-section of at least two slices was performed if bony union could not reliably be confirmed on standard radiographs.

The mean final follow-up was 67 months (17 to 90) after injury. Patients were asked about residual pain and restriction in their activities. Examination included assessment of ten- 
Table I. Synopsis of patient characteristics

\begin{tabular}{llllll}
\hline $\begin{array}{l}\text { Patient } \\
\text { number }\end{array}$ & $\begin{array}{l}\text { Age at accident } \\
\text { (yrs) }\end{array}$ & $\begin{array}{l}\text { Delay of diagnosis } \\
\text { (mths) }\end{array}$ & $\begin{array}{l}\text { Cast immobilisation } \\
\text { (mths) }\end{array}$ & $\begin{array}{l}\text { Mechanism of } \\
\text { injury }\end{array}$ & $\begin{array}{l}\text { Localisation of } \\
\text { fracture }\end{array}$ \\
\hline 1 & 9.7 & 5.5 & 4 & Snowboard & Waist \\
2 & 11.3 & 5 & 6 & Bike & Waist \\
3 & 14.4 & 7 & 6 & Skateboard & Distal \\
4 & 10.3 & 3 & $7^{*}$ & Running & Waist \\
5 & 14.8 & 4 & 3 & Snowboard & Waist \\
6 & 16.3 & 3 & 6 & Soccer & Waist \\
\hline
\end{tabular}

* two-month cast, five-month splint

Table II. Results after conservative treatment (figures in brackets refer to the uninjured side)

\begin{tabular}{|c|c|c|c|c|c|c|}
\hline $\begin{array}{l}\text { Patient } \\
\text { number }\end{array}$ & $\begin{array}{l}\text { Follow-up } \\
\text { (mths) }\end{array}$ & $\begin{array}{l}\text { Range of movement } \\
\left({ }^{\circ}\right)\end{array}$ & $\begin{array}{l}\text { Power grip } \\
\text { (kp) }\end{array}$ & $\begin{array}{l}\text { Return to regular } \\
\text { activity? }\end{array}$ & Pain & $\begin{array}{l}\text { Modified Mayo } \\
\text { Wrist Score }\end{array}$ \\
\hline 1 & 78 & $90 / 0 / 75(90 / 0 / 70)$ & $38(38)$ & Yes & No & 100 \\
\hline 3 & 76 & $85 / 0 / 75(85 / 0 / 80)$ & $36(34)$ & Yes & Mild occasional & 95 \\
\hline 4 & 90 & $\ldots \ldots \ldots{ }^{*}$ & .........* & Yes & No & $\dagger$ \\
\hline 5 & 61 & $90 / 0 / 60(90 / 0 / 60)$ & $34(31)$ & Yes & No & 100 \\
\hline
\end{tabular}

derness in the anatomical snuffbox, measurement of the arc of movement of the wrist, and assessment of grip strength using a Jamar dynamometer. The Modified Mayo Wrist Score could then be calculated. ${ }^{14}$ Radiographs of both hands were taken at the final follow-up and assessed by a surgeon $(\mathrm{RF})$ and a radiologist (JE) blinded to the side of the fracture. They were looking for signs of persistent nonunion, malunion and sclerotic changes to the scaphoid, as well as for malalignment or degenerative changes of the wrist.

\section{Results}

Union of the scaphoid was found in all patients after a mean of 5.3 months of immobilisation (3 to 7). All patients had returned to their regular activities, including sports. All were free of symptoms, apart from one who had mild pain when doing push-ups. The range of active movement of the wrist and grip strength were within $25 \%$ of the contralateral side and the Mayo Wrist Score was excellent in all patients (Table II).

At the final radiographic examination all fractures were united and there were no degenerative changes of the wrist joints. There were no articular step-offs at the scaphoid, but in three cases there was some shortening of the scaphoid, with a dorsal intercalated segment instability deformity in one of these three. The scaphoid with the most obvious shortening also showed some sclerotic and cystic changes. Five patients had no early treatment. Four of them did not seek medical attention; one had initial radiographs but the fracture was not visible (patient no. 2, Fig. 1). The fracture was initially diagnosed in only one patient, but nonunion occurred because of an inadequate period of immobilisation. He was the only patient with two series of cast immobilisation.

Cast immobilisation was tolerated by all patients, so that change to another treatment was unnecessary. One patient had a removable thermoplastic splint that allowed him to swim for the last few weeks of his treatment.

\section{Discussion}

This series describes successful conservative treatment of scaphoid nonunion in children and adolescents. Nevertheless, the number of patients is small, and conclusions should be drawn cautiously.

There are many definitions of nonunion and delayed union scaphoid of a fracture of the scaphoid. In the radiological literature, most authors define nonunion as a radiolucent line at the fracture site with local cystic changes or sclerosis on standard radiographs but they often disregard the time from injury. On the other hand, surgeons tend to identify the delay between injury and diagnosis in addition to the radiological signs when diagnosing a nonunion. For this study we used Osterman's definition of scaphoid nonunion, which includes an absence of bony fusion for at least three months after injury. ${ }^{12}$

Thus all our patients had a nonunion of the scaphoid. There was a mean delay of 5.3 months between injury and the start of conservative treatment, the longest delay being seven months, so conclusions cannot be extended to very latepresenting paediatric scaphoid nonunions.

The optimal treatment of non-displaced scaphoid nonunion in children and adolescents is controversial. Recommendations include immobilisation, sometimes supplemented 


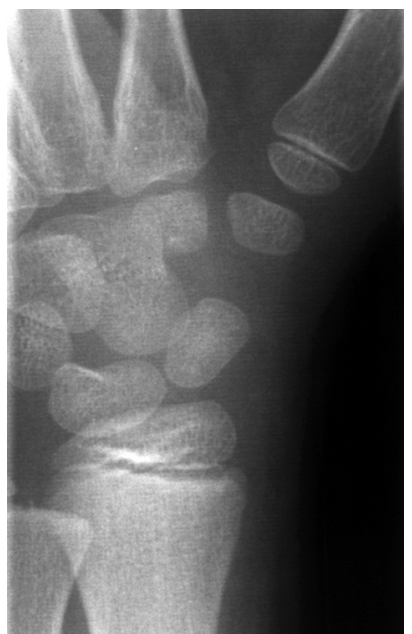

Fig. 1a

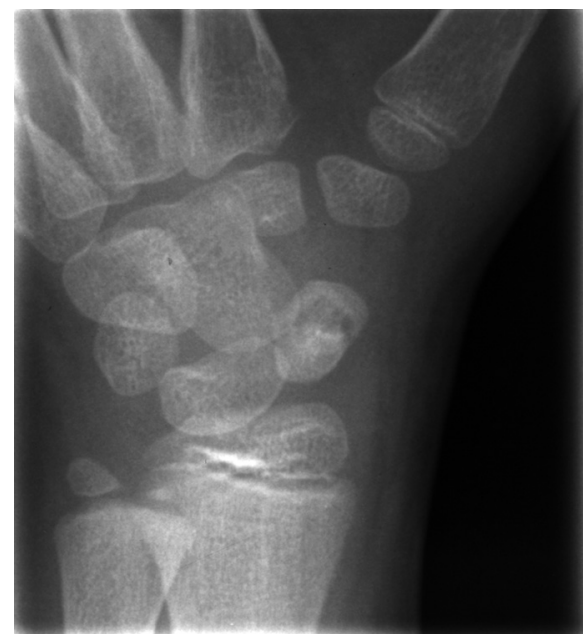

Fig. 1b

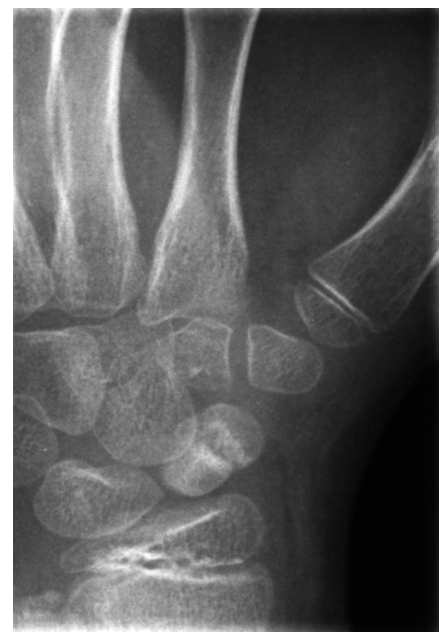

Fig. 1c

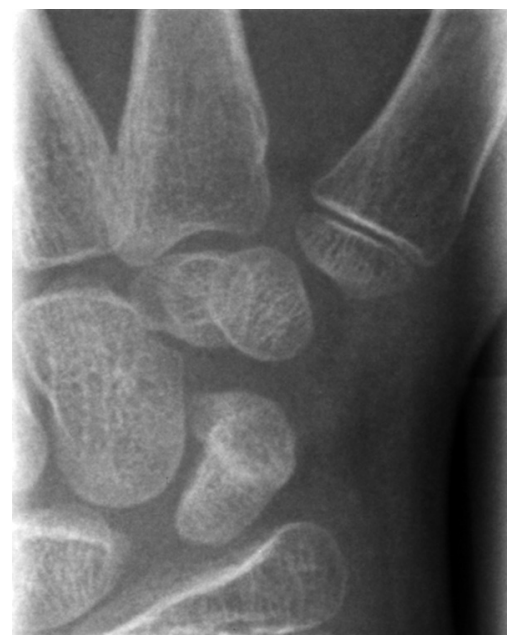

Fig. 1d

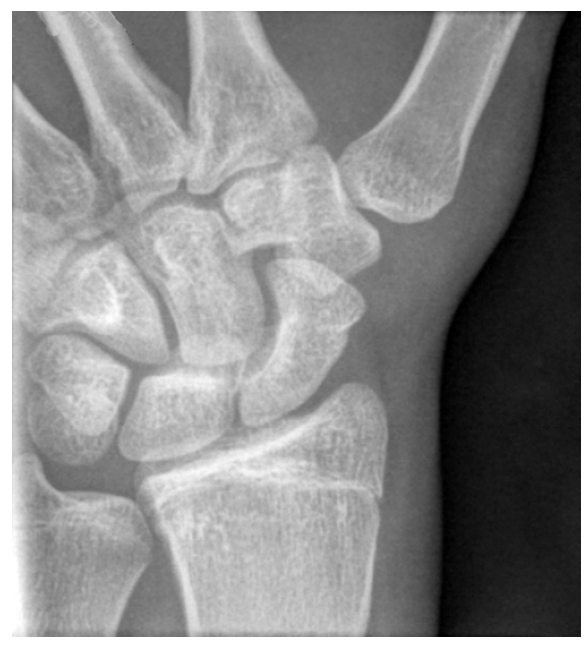

Fig. 1e

Radiograph a) five days after injury shows no signs of a scaphoid fracture; b) scaphoid nonunion six months after injury, before treatment starts; c) persistent nonunion with progressive sclerosis and widening of the fracture gap two months after immobilisation; d) union of the fracture after five months of immobilisation and e) at latest follow-up seven years after injury.

with shock-wave therapy, ${ }^{4}$ pulsed electromagnetic field stimulation ${ }^{15}$ or electrical stimulation. ${ }^{12}$ Furthermore, various surgical techniques with or without bone graftingand many

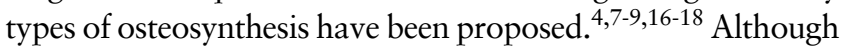
opinion supports the conservative management of paediatric scaphoid nonunion with prolonged immobilisation, ${ }^{2,4,19}$ only a few cases have been reported. Fewer than 20 children with conservative treatment have been reported in the English literature. ${ }^{3,5,6}$ Most had a favourable outcome, although in one series of four patients, one required operative intervention for persistent nonunion. ${ }^{5}$

There are reports of successful conservative treatment of non-displaced scaphoid nonunions in adults, some presenting more than a year after injury. ${ }^{12,20}$ Mazet and Hohl ${ }^{20}$ demonstrated that immobilisation in plaster was successful when it was continued for long periods, sometimes up to 22 months. ${ }^{12}$ However, nowadays, particularly with the introduction of the Herbert screw, ${ }^{21}$ prolonged immobilisation is considered a potential risk, causing economic loss, stiffness of joints and osteoporosis. ${ }^{22}$ Fortunately, in children the scaphoid has a more favourable healing capacity than in adults. ${ }^{23}$ Union seems to occur faster and more reliably, and the growing scaphoid may even have a remodelling capacity, enabling it to correct minor degrees of malunion. ${ }^{24}$

In children, stiffness and osteoporosis do not seem to be an issue, and full recovery can be expected even if prolonged immobilisation is required. Despite this, most studies on paediatric nonunions describe operative treatment. ${ }^{7,9,10}$ Most authors regard an established nonunion as an indication for 
surgery, and discussion focuses on the type of surgery rather than on whether or not surgery is indicated. Comparison of these studies is difficult, because the authors do not adhere to the same definitions of nonunion, and outcome parameters are not standardised. Toh et $\mathrm{al}^{10}$ described the range of movement and grip strength of their patients who underwent surgical treatment, which were $89 \%$ and $92 \%$ of the contralateral side, results that are comparable with our series. Fabre et $\mathrm{al}^{3}$ confirmed that a full range of movement can be achieved after prolonged conservative treatment.

Information on carpal instability is scarce. In their series of 20 children with an un-united fracture of the scaphoid treated surgically, Henderson and Letts ${ }^{9}$ reported two patients who developed carpal collapse. Because no long follow-ups of paediatric scaphoid nonunions have been reported, the eventual risk for proximal row instability is not known, and we consider that these patients should be followed until adulthood.

The duration of immobilisation is an important issue. Chloros et $\mathrm{al}^{7}$ presented a group of 12 skeletally immature patients with scaphoid nonunion that seems to be comparable to ours, although the time from injury to diagnosis was not specified. All patients were treated with open reduction and internal fixation using a Herbert screw, and the results achieved were comparable to ours. ${ }^{7}$ Clinical and radiographic union could be documented at a mean of 3.4 months, compared to the 5.3 months in our series. As in adults, screw immobilisation, particularly when performed percutaneously, may allow an earlier return to activities. ${ }^{15}$ Whereas the economic loss is not usually an issue in children, exclusion from activities may not be socially acceptable for some adolescents, particularly those who are involved in competitive sports or with other exceptional commitments. However, the advantage of a quicker recovery must be balanced against the potential risks and cost of surgery. Therefore, we routinely recommend cast immobilisation for at least three months in all non-displaced paediatric scaphoid nonunions that have not had a previous trial of conservative treatment. In those who have a nonunuion due to inadequate primary immobilisation, casts can still be offered as a valuable alternative to surgery.

We thank R. Bochud for the acquisition and examination of patients, and J. Ederer, Department of Radiology, Kantonsspital Bruderholz, for assessment of the radiographs.
No benefits in any form have been received or will be received from a commercial party related directly or indirectly to the study of this article.

\section{References}

1. Waters PM. Operative carpal and hand injuries in children. J Bone Joint Surg [Am] 2007:89-A:2064-74.

2. Light TR. Carpal injuries in children. Hand Clin 2000;16:513-22.

3. Fabre O, De Boeck H, Haentjens P. Fractures and nonunions of the carpal scaphoid in children. Acta Orthop Belg 2001;67:121-5.

4. D'Arienzo M. Scaphoid fractures in children. J Hand Surg [Br] 2002;27:424-6.

5. Greene MH, Hadied AM, LaMont RL. Scaphoid fractures in children. J Hand Surg [Am] 1984;9:536-41.

6. Vahvanen $\mathbf{V}$, Westerlund $\mathbf{M}$. Fracture of the carpal scaphoid in children: a clinical and roentgenological study of 108 cases. Acta Orthop Scand 1980;51:909-13.

7. Chloros GD, Themistocleous GS, Wiesler ER, et al. Pediatric scaphoid nonunion. $J$ Hand Surg [Am] 2007;32:172-6.

8. Duteille F, Dautel G. Non-union fractures of the scaphoid and carpal bones in children: surgical treatment. J Pediatr Orthop B 2004;13:34-8.

9. Henderson B, Letts $\mathbf{M}$. Operative management of pediatric scaphoid fracture nonunion. J Pediatr Orthop 2003;23:402-6.

10. Toh S, Miura H, Arai K, et al. Scaphoid fractures in children: problems and treatment. J Pediatr Orthop 2003;23:216-21.

11. Ramamurthy C, Cutler L, Nuttall D, et al. The factors affecting outcome after nonvascular bone grafting and internal fixation for nonunion of the scaphoid. J Bone Joint Surg [Br] 2007;89-B:627-32.

12. Osterman AL, Mikulics M. Scaphoid nonunion. Hand Clin 1988;4:437-55.

13. Watson HK, Ashmead D 4th, Makhlouf MV. Examination of the scaphoid. J Hand Surg [Am] 1988;13:657-60.

14. Cooney WP, Bussey R, Dobyns JH, Linscheid RL. Difficult wrist fractures: perilunate fracture-dislocations of the wrist. Clin Orthop 1987;214:136-47.

15. Godley DR. Nonunited carpal scaphoid fracture in a child: treatment with pulsed electromagnetic field simulation. Orthopedics 1997;20:718-19.

16. McQueen MM, Gelbke MK, Wakefield A, Will EM, Gaebler C. Percutaneous screw fixation versus conservative treatment for fractures of the waist of the scaphoid: a prospective randomised study. J Bone Joint Surg [Br] 2008;90-B:66-71.

17. Thompson NW, Kapoor $\mathbf{A}$, Thomas $\mathbf{J}$, Hayton MJ. The use of a vascularised periosteal patch onlay graft in the management of nonunion of the proximal scaphoid. $J$ Bone Joint Surg [Br] 2008;90-B:1597-601.

18. Veitch S, Blake SM, David H. Proximal scaphoid rib graft arthroplasty. J Bone Joint Surg [Br] 2007;89-B:196-201.

19. Beaty JH, Kasser JR. Specific carpal fractures. In: Rockwood and Wilkins Fractures in children. Fifth ed. Philadelphia: Lippincott Williams and Wilkins 2001:342-53.

20. Mazet R, Hohl M. Fractures of the carpal navicular: analysis of ninety-one cases and review of the literature. J Bone Joint Surg [Am] 1963;45-A:82-112.

21. Filan SL, Herbert TJ. Herbert screw fixation of scaphoid fractures. J Bone Joint Surg [Br] 1996;78-B:519-29.

22. Gupta A, Risitano G, Crawford RJ, Burke FD. The ununited scaphoid: prognostic factors in delayed and nonunions of the scaphoid. Hand Surg 1999;4:11-19.

23. Garcia-Mata S. Carpal scaphoid fracture nonunion in children. J Pediatr Orthop 2002;22:448-51.

24. Suzuki K, Herbert TJ. Spontaneous correction of dorsal intercalated segment instability deformity with scaphoid malunion in the skeletally immature. J Hand Surg [Am] 1993;18:1012-15 